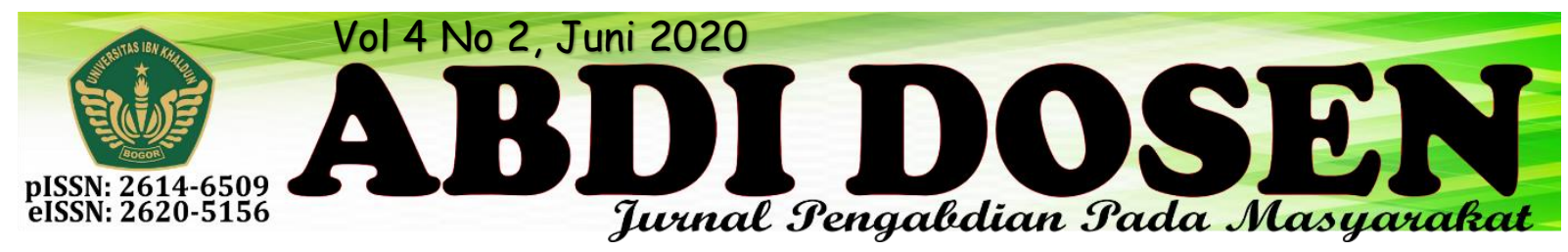

\title{
MENGEMBANGKAN KUALITAS SUMBER DAYA MANUSIA MELALUI PENINGKATAN MUTU PENDIDIKAN, KESEHATAN DAN PEREKONOMIAN DESA BARENGKOK
}

\author{
M Imam Sundarta ${ }^{1}$, Putri Ria Angelina ${ }^{2}$, Iyus Sidik Akbar, Isnaini Lailatul Rohmah ${ }^{3}$ \\ imam@uika-bogor.ac.id ${ }^{1}$ \\ putri@uika-bogor.ac.id ${ }^{2}$ \\ iyussidikakbar@gmail.com, isnaini@gmail.com ${ }^{3}$ \\ Dosen Fakultas Ekonomi dan Bisnis ${ }^{1}$, Dosen Fakultas Keguruan dan Ilmu Pendidikan², Mahasiswa KKN
}

Kelompok 09\&10 Tahun $2019^{3}$

\begin{abstract}
ABSTRAK
Penelitian ini bertujuan untuk memberdayakan dan membangun masyarakat Desa Barengkok melalui bidang pendidikan, kesehatan dan perekonomian, dengan menggunakan penerapan metode Participatory Rural Appraisal (PRA) Penelitian ini merupakan Penelitian Deskriptif pencarian fakta dengan interpretasi yang tepat. Penelitian deskriptif mempelajari masalahmasalah dalam masyarakat serta tata cara yang berlaku dalam masyarakat serta situasi-situasi tertentu, termasuk tentang hubungan, kegiatan-kegiatan, sikap-sikap, pandangan-pandangan, serta proses-proses yang sedang berlangsung dan pengaruh-pengaruh dari suatu fenomena. Dengan metode deskriptif ini juga diselidiki kedudukan (status) fenomena atau faktor dan melihat hubungan antara satu faktor dengan faktor lainnya. Karenanya metode deskriptif juga dinamakan studi status (status study). Penelitian dalam bidang pendidikan, kesahatan dan perekonomian kami lakukan di Kp. Barengkok RW 001 dan RW 003.
\end{abstract}

\section{Kata kunci :Sumber Daya Manusia, Peningkatan Mutu, Metode Deskriptif}

\section{PENDAHULUAN}

\section{Latar Belakang}

Konsep pemberdayaan pada perkembangan memiliki banyak definisi yang dikemukakan oleh para ahli yang memiliki komitmen tinggi terhadap usaha memajukan kesejahteraan masyarakat, seperti yang dikemukakan oleh Ife (1995 182), yaitu pemberdayaan berarti menyiapkan kepada masyarakat berupa sumberdaya, kesempatan, pengetahuan, dan keahlian untuk meningkatkan kapasitas diri masyarakat didalam menentukan masa depan mereka, serta untuk berpartisipasi dan mempengaruhi kehidupan dalam komunitas masyarakat itu sendiri.

Terkait dengan tujuan pemberdayaan, Sulistiyani (2004) menjelaskan bahwa tujuan yang ingin dicapai dari pemberdayaan masyarakat adalah untuk membentuk individu dan masyarakat menjadi mandiri. Kemandirian tersebut meliputi kemandirian berfikir, bertindak, dan mengendalikan apa yang mereka lakukan. Perlunya upaya untuk pemberdayaan adalah berangkat dari kenyataan masih lemahnya posisi sebagian besar masyarakat dalam menuntut hak dan menjalankan kewajibannya ditunjukan 
dengan kurang aksesnya mereka terhdap beberapa fasilitas, misalnya pendidikan, informasi, teknologi, permodalan usaha, hukum, dan kesehatan. Berbagai kelemahan akses tersebut diawali dengan rendahnya tingkat pendidikan yang dimiliki oleh masyarakat kita terutama diperdesaan yang ada dikampung Geledug RT 05 RW 03, Desa Barengkok, Kec. Leuwiliang, Kab. Bogor

Pelaksanaanya dalam masyarakat ataupun dieujudkan dengan pelatihan atau skill, mengajar, penyuluhan, dan tak lupa menanamkan pentingnya ahlak dalam segala aspek kehidupan. Seperti yang dikatakan Al-Ghazali "ketika manusia mempunyai ilmu namun sulit untuk memahami jangan-jangan ada yang keliru, karena ilmu itu merupakan nur atau cahaya jadi kemungkinan ada yang menghalangi masuknya nur kedalam otak dan jiwa kita" pentingnya memelihara ahlak atau adab agar senantiasa terarah dan dalam keridhaannya.

\section{Kondisi wilayah}

Letak geografis dan administrasi Desa Barengkok, secara geografis terletak pada $682500^{\circ}, 679500^{\circ}$ UTM dan $92696500^{\circ}-9272000^{\circ} \quad$ UTM. Secara administratif Desa Barengkok termasuk ke dalam Kecamatan Leuwiliang, Kabupaten Bogor, Provinsi Jawa Barat. Batas-batas administratif Desa Barengkok adalah :

Sebelah Utara: Desa Leuwimekar

Sebelah Timur: Situ Ilir Kecamatan

Cibungbulang

Sebelah Selatan: Desa Karacak

Sebelah Barat: Desa Cibeber II
Secara topografi Desa Barengkok berada dalam dataran rendah, yakni pada ketinggian $120 \mathrm{~m}$ sampai dengan $200 \mathrm{~m}$ di atas permukaan laut. Desa Barengkok memiliki lahan sebesar 450ha, dengan jumlah penduduk sebanyak 12.134 jiwa yang terdiri dari 6.240 jiwa laki-laki dan 5.894 perempuan, dengan jumlah keluarga sebanyak 3.435 keluarga.

\section{Luas Wilayah}

Jumlah luas tanah Desa Barengkok seluruhnya mencapai 450 ha, Jarak Desa Barengkok dengan Kecamatan Leuwiliang adalah 1,5 km. Dengan Kabupaten Bogor $42 \mathrm{~km}$, Ibu kota provinsi $142 \mathrm{~km}$, dan ibu kota negara $82 \mathrm{~km}$. Penduduk Desa Barengkok mayoritas sebagai petani sebanyak 1.559 orang, sedangkan jumah penduduk yang bermata pencaharian di sektor perdagangan mencapai 1.257 orang. Sisanya di peternakan, kehutanan, supir, buruh pabrik, PNS, penjahit, dan perikanan dengan jumlah yang tiak pasti.

a. Keadaan Administratif Desa Barengkok Desa Barengkok terbagi atas 14 kampung :

1). Kampung Barengkok

2). Kampung Dahu

3). Kampung Cibata

4). Kampung Citeureup

5). Kampung Kandang Sapi

6). Kampung Bukit Sakinah

7). Kampung Geledug

8). Kampung Munara

9). Kampung Sawah Baru

10). Kampung Saninten

11). Kampung Warung Salak

12). Kampung Jadir

13). Kampung Cikopeah

14). Kampung Bantar Endah 


\section{METODE PENGABDIAN}

Partisipasi masyarakat sudah lebih dari satu dasawarsa menjadi kata kunci dalam bahasa masyarakat pembangunan. Namun dalam kenyataannya program pembangunan dan pengembangan msyarakat masih juga dilakukan dengan cara lama yang mengabaikan konsep partisipasi. Program pembangunan masih saja diturunkan dari atas dan masyarakat tinggal melaksanakannya tanpa adanya keterlibatan langsung masyarakat yang menjadi sasaran program tersebut. Kalaupun ada penjajagan terhadap kebutuhan pembangunan, itupun dilakukan dengan cara survai, studi atau penelitian formal yang dilakukan oleh lembaga penelitian atau perguruan tinggi yang karena beberapa asumsi yang kurang tepat, maka program tidak menyentuh kebutuhan yang sesungguhnya. Dengan sendirinya dukungan masyarakat terhadap program tersebut menjadi pura-pura, demikian pula partisipasinya. Yang berpengaruh terhadap keberlanjutan dari program tersebut.

Alasan-alasan yang demikian melahirkan beragam pemikiran tentang pendekatan pengembangan program yang lebih partisipatif. Istilah-istilah partisipasi masyarakat, perencanaan dari bawah (bottom-up planning), penyadaran, pendekatan yang berpusat pada masyarakat (fcommunity centered approach), dll menjadi kosa kata para aktivis pembangunan, baik pemerintah maupun swasta, walaupun kenyataannya belum mencerminkan arti kata tersebut. Programprogram yang ada masih saja tetap diturunkan dari atas (top-down approach), direncanakan dari meja kantor, sementara masyarakat diperkenankan berpartisipasi dalam pelaksanaan fisik di lapangan, sehingga tingkatan partisipasinya masih layak disebut sebagai mobilisasi.

Demikian mendorong untuk diperkenalkannya salah satu metode dan teknik yang dikenal dengan Participatory Rural Appraisal (PRA), karena dipandang telah memiliki teknikteknik yang dijabarkan cukup operasional dengan konsep bahwa keterlibatan masyarakat sangat diperlukan dalam seluruh kegiatan. Pendekatan PRA memang bercita-cita menjadikan masyarakat menjadi peneliti, perencana, dan pelaksana pembangunan dan bukan sekedar obyek pembangunan. Tekanan aspek penelitian bukan pada validitas data yang diperoleh, namun pada nilai praktis untuk pengembangan program itu sendiri. Penerapan pendekatan dan teknik PRA dapat memberi peluang yang lebih besar dan lebih terarah untuk melibatkan masyarakat. Selain itu melalui pendekatan PRA akan dapat dicapai kesesuaian dan ketepatgunaan program dengan kebutuhan masyarakat sehingga keberlanjutan (sustainability) program dapat terjamin.

PRA adalah suatu metode pendekatan untuk mempelajari kondisi dan kehidupan pedesaan dari, dengan, dan oleh masyarakat desa. Atau dengan kata lain dapat disebut sebagai kelompok metode pendekatan yang memungkinkan masyarakat desa untuk saling berbagi, meningkatkan, dan menganalisis pengetahuan mereka tentang kondisi dan kehidupan desa, membuat rencana dan bertindak (Chambers, 1995). 
Tahapan pelaksanaan untuk kegiatan ini sebagaimana terlihat pada bagan sebagai berikut:

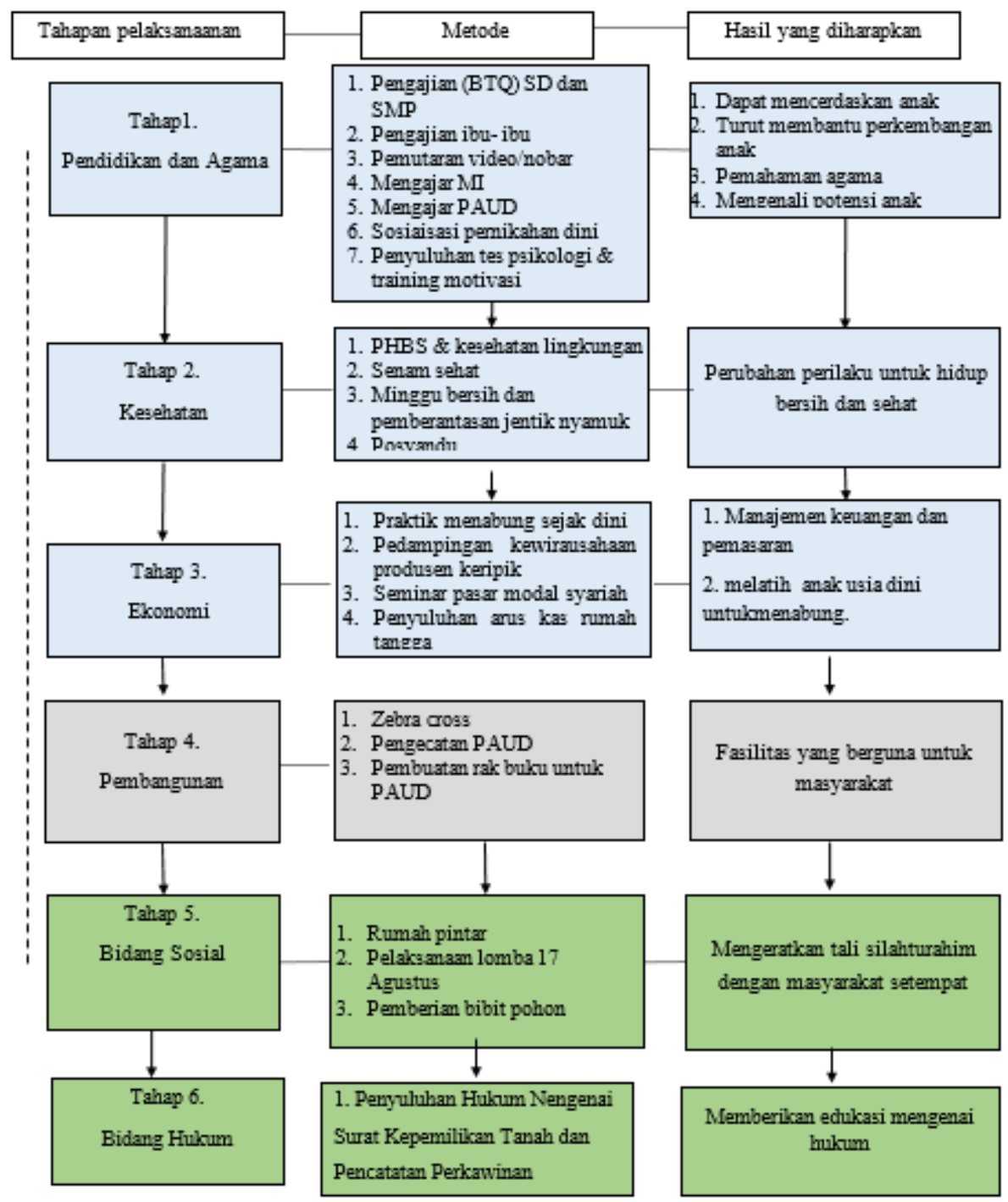

Tabel Jadwal kegiatan

\begin{tabular}{|c|l|c|c|c|c|}
\hline No & \multicolumn{1}{|c|}{ Kegiatan } & \multicolumn{3}{|c|}{ Minggu ke- } \\
\hline & \multicolumn{1}{|c|}{} & 1 & 2 & 3 & 4 \\
\hline 1. & Penyusunan Rencana Kegiatan & & & & \\
\hline 2. & Pengajian (BTQ) SD Dan SMP & & & \\
\hline 3. & Pengajian Ibu- Ibu & & & \\
\hline 4. & Mengajar MI Mafazah & & & \\
\hline 5. & Mengajar PAUD Perkutut & & & \\
\hline 6. & Sosiaisasi Pernikahan Dini & & & \\
\hline 7. & PHBS \& Kesehatan Lingkungan & & & \\
\hline 8. & Senam Sehat & & & \\
\hline 9. & Minggu Bersih Dan Pemberantasan Jentik Nyamuk & & \\
\hline
\end{tabular}




\begin{tabular}{|c|l|l|l|l|}
\hline 10. & Posyandu\& Poslansia & & & \\
\hline 11. & Praktik Menabung Sejak Dini & & & \\
\hline 12. & Pendampingan Kewirausahaan Produsen Keripik & & & \\
\hline 13. & Penyuluhan Arus Kas Rumah Tangga & & & \\
\hline 14. & Seminar Pasar Modal & & & \\
\hline 15. & Pengecatan Zabra Cross & & & \\
\hline 16. & Pengecatan PAUD & & & \\
\hline 17. & Pembuatan Rak Buku Untuk PAUD & & & \\
\hline 18. & Penyuluhan Tes Psikologis \& Training Motivasi & & \\
\hline 19. & Rumah Pintar & & & \\
\hline 20. & Pelaksanaan Lomba 17 Agustus & & & \\
\hline 21. & Pemberian Bibit Pohon & & \\
\hline
\end{tabular}

\section{REALISASI PROGRAM}

Pelaksanaan program kerja KKN 9 dan 10 selama 1 bulan terhitung mulai tanggal 6 Agustus sampai 6 september 2019 di kampung Barengkok RT/RW 02/01 desa Barengkok, Kec. Leuwiliang, Kab. Bogor adalah sebagai berikut:

\section{A. Bidang Pendidikan dan Agama} TPQ (Taman Pendidikan AlQuran)

TPQ adalah lembaga atau kelompok masyarakat yang menyelenggarakan pendidikan nonformal jenis kegiatan keagamaan islam yang bertujuan untuk memberikan pengajaran membaca AlQuran sejak usia dini, serta memahami dasar-dasar Islam pada anak usia sekolah dasar dan sekolah menengah atas. Program ini dilaksanakan oleh bidang Agama setiap hari Senin-Sabtu pukul 15.30 WIB bertepatan di TPQ Shihabul Huda.

\section{Seminar Pernikahan Dini}

Kami melaksanakan Seminar Pernikahan Dini pada hari Selasa, 27 Agustus 2019 di selenggarakan di sekolah Nurul Iman Al-Hasanah merupakan kegiatan yang dilakukan untuk mengeduksi masyarakat mengenai dampak pernikahan dini Yang membahas dari sisi Psikologi, hukum Islam maupun hukum positif.

\section{Mengajar}

Mengajar adalah menanamkan pengetahuan kepada anak didik dengan harapan terjadi proses pemahaman melalui pemberian informasi atau pengetahuan yang kami berikan kepada siswa. Mengajar kami laksanakan di MI Mafazah, MA Mafazah, PAUD Perkutut, dan Rumah Pintar setiap hari senin-sabtu.

\section{Nonton bareng/ NOBAR}

Dilaksanakan pada hari Kamis, 14 Agustus 2019 Kegiatan ini dilaksanakan di rumah pintar, kami menanyangkan video untuk memeberikan wawasan agar anak anak tidak terpengaruh dengan permainan ysng ada didalam gadget serta tidak melupakan permainan tradisiona yang harusnya dimainkan oleh anak - anak .

Penyuluhan Tes Psikologis dan Training Motivasi

Tes Minat dan Bakat merupakan salah satu metode dan alat ukur dalam Psikologi yang dapat membantu dalam menyusun rekomendasi untuk individu memilih jurusan/karir sesuai dengan minat dan potensinya. Pengukuran psikologi menjadi salah satu kebutuhan dalam berbagi aspek kehidupan moderen saat ini. Tidak dapat dipungkiri, kemajuan teori dan penelitian telah melahirkan beragam 
metode dan alat ukur untuk mengukur berbagai aspek psikologis individu. Dimulai dengan kemajuan pengukuran inteligensi, kepribadian, hingga penggunaannya menjadi ide dasar untuk penerapan diberbagai aspek.

Dalam hal ini Tes Bakat fokus pada mengukur kemampuan yang lebih spesifik namun juga memberikan informasi kemampuan lainnya yang bersifat beragam (multiple) kemampuan. Tes bakat mengukur suatu sampel tingkah laku yang secara diagnosis dapat memprediksi perilaku lainnyadimasa yang akan datang. Sehingga fungsi tes bakat dapat digunakan untuk meramalkan performance seseorang dikemudian hari. Hal ini didapatkan dari hasil pengalaman dan proses belajar individu yang diukur dalam tes.

\section{B. Bidang sosial}

\section{Pembudidayaan Dan Penanaman Bibit Pohon Bisbul}

Kegiatan ini merupakan salah satu bentuk pelestarian tanaman yang tergolong langka, kami laksanakan dengan cara pemberian bibit Pohon kepada masingmasing RT di Desa Barengkok hal penting lainnya terkait fungsi pohon, seperti yang kita ketahui bahwa pohon adalah menciptakan udara bersih atau oksigen (O2) yang manusia butuhkan dan sebaliknya dapat menyerap $\mathrm{CO} 2$ yaitu udara kotor hasil gas buangan sisa pembakaran, jadi secara hygienis, pohon sangat berguna bagi kehidupan manusia.

\section{Pelaksanaan Lomba 17 Agustus}

Dilaksanakan pada hari Sabtu, 17 Agustus 2019 acara ini dilaksanakan di RT/RW 02/01 dan RT/RW 05/03 Desa Barengkok. Maksud dari pelaksanaan 17 Agustus ini adalah untuk memeriahkan hari ulang tahun Indonesia ke-74 dengan melakukan beberapa kegiatan perlombaan yang diikuti oleh warga kampung Geledug dan kampung barengkok.

\section{Bidang Hukum}

\section{Penyuluhan Hukum Mengenai Surat} Kepemilikan Tanah dan Pencatatan Perkawinan

Dilaksanakan pada hari Rabu, 28 Agustus 2019 dikantor kecamatan Leuwiliang, Penyuluhan Hukum ini sangat berguna bagi masy arakat dikarenakan dibeberapa desa di kecamatan Leuwiliang masih banyak warga yang buta akan hukum atau belum mengetahui mengenai aturan tentang surat kepemillikan tanah dan pencatatan perka winan yang sangat penting untuk masyarakat sebagai landasan hukum yang kuat. Dengan adanya penyuluhan tersebut masyarakat dapat teredukasih dan sedikit mengerti mengenai Hukum.

\section{Bidang Ekonomi}

\section{Praktik Menabung Sejak Dini}

Kami melaksanakan penyuluhan gemar menabung pada Kamis, 22 Agustus 2019 dan Senin, 26 Agustus 2019 di MI Mafazah. Menabung merupakan kegiatan yang baik untuk di pupuk dan dibiasakan sejak dini karena dengan menabung dapat memberikan dampak positif bagi anakanak untuk belajar berhemat dan bertanggung jawab dalam memegang uang selain itu kami juga memberikan celengan dari daur ulang botol bekas yang telah di hias agar lebih menarik dan yang menabung paling banyak kami berikan hadiah.

\section{Pendampingan \\ Produsen Keripik \\ Kewirausahaan}

Program ini kami lakukan untuk membantu salah satu UKM keripik pisang di Desa Barengkok guna meningkatkan perekonomian sehingga menemukan solusi dari permasalahan ekonomi yang ada di UKM, agar dapat mengelola keuangan 
dengan baik, dan dapat memilih kebutuhan dan pengeluaran yang harus di prioritaskan nya atas dasar itu kami membantu dalam hal penjualan, pembukuan keuangan, branding, serta memberikan peralatan yang dibutuhkan untuk proses produksi agar lebih efektif dan efisien.

\section{Seminar Edukasi Pasar Modal Syariah}

Dilaksanakan pada hari Rabu, 21

Agustus 2019, Edukasi tentang pasar modal syariah merupakan suatu media pengembangan minat keuangan bagi masyarakat umum. Kegiatan ini merupakan sebuah usulan dari sebuah Kelompok Studi Pasar Modal Syariah (KSPM) Universitas Ibn Khaldun Bogor untuk di adakan di Kecamatan Leuwiliang dan melibatkan mahasiswa Universitas Ibn Khaldun Bogor yang sedang menjalani Kuliah

Kerja Nyata (KKN) sebagai panitia acara Edukasi tentang Pasar Modal Syariah. Mengingat pentingnya investasi bagi masyarakat indonesia, maka kegiatan ini sangat perlu untuk diadakan supaya masyarakat bisa memahami investasi yang benar menurut syariat.

\section{Penyuluhan Arus Kas Rumah Tangga}

Dilaksanakan Selasa, 20 Agustus 2019 Program tersebut diikuti oleh ibu-ibu majelis ta'lim. Tujuan diadakannya penyuluhan arus kas dalam rumah tangga adalah untuk memberikan wawasan bagaimana mengelola keuangan yang baik dan tercatat rapi mulai dari pemasukan dan pengeluaran uang serta menyisihkan uang untuk ditabung agar semua kebutuhan rumah tangga tercukupi

\section{E. Bidang Pembangunan}

\section{Zebra Cross}

Dilaksanakan pada Minggu, 01 September 2019. Zebra cross adalah tempat penyebrangan di jalan yang diperuntukan untuk Pejalan kaki yang akan menyebrang jalan. Pengecatan zebra cross ini di lakukan untuk Meningkatkan keamanan lalu lintas di area sekolah MI Mafazah sehingga tidak terjadi kecelakaan anak-anak ketika sedang menyebrang jalanan dan memberikan keamanan terhadap sekolah MI Mafazah.

\section{Pengecatan PAUD}

Dilaksanakan pada Sabtu, 31 Agustus 2019 pengecatan PAUD ini bertujuan Untuk memperindah ruang kelas PAUD dan menambah semangat belajar peserta didik untuk bertujuan menghadirkan warna dan keceriaan untuk anak-anak sehingga menambahkan motivasi dan semangat belajar anak-anak untuk datang ke sekolah khususnya di ruang kelas untuk anak-anak tersebut agar kegiatan ngajar mengajar menjadi nyaman dan menyenangkan, sehingga dapat menculnya keinginan belajar yang lebih semangat dan PAUD dapat menambah jumlahpeserta didik di tahun yang akan datang.

\section{Pembuatan Rak Buku Untuk PAUD}

Dilaksanakan Kamis, 05 September 2019 program ini bertujuan agar ruang kelas terlihat lebih rapi dan tertata, untuk menggiatkan budaya literasi PAUD tersebut, sekaligus kami memberikan buku-buku untuk dipergunakan oleh anakanak.

\section{F. Bidang Kesehatan \\ PHBS \& Kesehatan Lingkungan}

Dilaksanakan Sabtu, 24 Agustus 2019 PHBS adalah semua Perilaku kesehatan yang dilakukan karna kesadaran pribadi. Dilaksanakan di MI Mafazah tujuan dari penyuluhan PHBS ini adalah memberdayakan setiap siswa, guru, dan masyarakat lingkungan sekolah agar tahu, mau, dan mampu menolong diri sendiri di bidang PHBS dan berperan aktif dalam mewujudkan sekolah sehat. 


\section{Senam Sehat}

Dilaksanakan pada hari Minggu, 18 Agustus 2019 Senam adalah kegiatan utama yang paling bermanfaat dalam mengembangkan komponen fisik dan kemampuan gerak (Motorability) sehat menurut WHO adalah suatu keadaan sejahtera yang meliputi fisik mental dan sosial, yang tidak hanya bebas dari penyakit atau kecacatan, sehingga senam sehat adalah kegiatan yang bermanfaat bagi kesehatan masyarakat

\section{Minggu Bersih Dan Pemberantasan Jentik Nyamuk}

Dilaksanakan pada hari Minggu, 25 Agustus 2019 Penyuluhan ini kami petugas kesehatan, kegiatan yang kami lakukan di posyandu antara lain, Kesehatan ibu dan anak (KIA), Program KB,

\section{KESIMPULAN}

KKN merupakan salah satu mata kuliah wajib bagi mahasiswa untuk mengabdikan diri kepada masyarakat. Hal ini ditujukan untuk melatih mahasiswa dalam hidup bermasyarakat serta untuk memberdayakan masyarakat dengan cara meningkatkan kreativitas dan kemampuan, membantu masyarakat melakukan fungsi keluarga melalui program-program.

\begin{tabular}{llrrr} 
a. & Pelaksanaan & \multicolumn{2}{c}{ kegiatan } & \multicolumn{2}{r}{ Bidang } \\
Pendidikan & dan & Agama & dari \\
mahasiswa & KKN & 9 & dan & 10
\end{tabular} mendapatkan respon yang positif dari masyarakat sekitar. Dengan adanya kegiatan pendidikan dan agama dari mahasiswa KKN 9 dan 10 Universitas Ibn Khaldun warga merasa mendapatkan wawasan baru baik dari segi agama, kesehatan, teknologi, ekonomi, dan pemberdayaan lingkungan . Namun, kendala di dalam pelaksanaan kegiatan dibidang laksanakan bersama warga Desa Barengkok Rt.05, tujuan kegiatan ini adalah untuk memberikan edukasi kepada masyarakat agar dapat menjaga lingkungan sekitar, agar tetap bersih. Sekaligus memberikan pemahaman untuk tidak membiarkan genangan air yang kotor disekitar rumah karna dapat menyebabkan berkembangnya jentik nyamuk yang bisa menimbulkan penyakit demam berdarah.

\section{Posyandu}

Dilaksanakan pada hari, Senin, 19 Agustus 2019 kegiatan posyandu adalah kegiatan kesehatan dasar yang di selenggarakan dari, oleh dan untuk masyarakat yang dibantu oleh Imunisasi, Gizi, dan Penanggulangan diare.

pendidikan ini adalah waktu yang tidak menungkinkan untuk mengajar setiap hari, Kendala lain adalah kurangnya tenaga pengajar, maka kami mahasiswa KKN 9 dan 10 yang harus terjun langsung ke sana, yang kami lakukan dalam 1 minggu 2 kali.

b. Pelaksanaan kegiatan Bidang Kesehatan dari mahasiswa KKN 9 dan 10 mendapatkan respon yang positif dari masyarakat sekitar. Dengan adanya kegiatan kesehatan dari mahasiswa KKN 9 dan 10 Universitas Ibn Khaldun warga merasa senang ketika kami melakukan penyuluhan PHBS \& kesehatan lingkungan, Senam sehat, Minggu bersih dan pemberantasan jentik nyamuk. Dengan bekerja sama dengan lembaga kesehatan seperti posyandu, dan ibuibu di sekitar kampung Geledug mahasiswa KKN 9 dan 10 memberikan penyuluhan dan 
pemberian imunisasi bagi balita dan pemberian bubuk abate untuk mencegah jentik nyamuk berkembang di genagan air pada rumah warga.

c. Pelaksanaan kegiatan Bidang Ekonomi dari mahasiswa KKN 9 dan 10 Universitas Ibn Khaldun mendapatkan respon yang positif dari UKM produsen keripik pisang program ini kami lakukan untuk membantu salah satu UKM keripik pisang di Desa Barengkok guna meningkatkan perekonomian nya atas dasar itu kami membantu dalam hal penjualan, pembukuan keuangan, branding, serta memberikan perlatanyang dibutuhkan untuk proses produksi agar lebih efektif dan efisien

d. Pelaksanaan kegiatan pada bidang pembangunan dalam bidang ini Mahaiswa kelompok 9 dan 10 melakukan beberapa kegiatan seperti pengecatan zebra cross di lakukan untuk meningkatkan keamanan lalu lintas di area sekolah MI Mafazah, pengecatan PAUD bertujuan untuk memperindah ruang kelas PAUD dan menambah semangat belajar peserta didik, dan pemberian rak buku untuk PAUD ini bertujuan agar ruang kelas terlihat lebih rapi dan tertata, sekaligus kami memberikan juz amma untuk dipergunakan olehanak-anak.

e. Pelaksanaan kegiatan pada bidang sosial kami kelompok 9 dan 10 melakukan kegiatan di rumah pintar dengan memberikan berbagai pembelajaran, baik mengajar tentang pendidikan, sosial, mengajar angklung, paskibra, menari, dan lain sebagainya. Selain itu kegiatan sosial lainnya adalah budidaya bibit pohon misbul yang telah kami bagikan ke masing-masing RT, sebagai bentuk pelestarian lingkungan Kampung Barengkok. 


\section{DAFTAR PUSTAKA}

Data Desa Barengkok Kecamatan Leuwiliang

Ikhsan, MZ., Prasetya, EP. (2020). Sosialisasi Pendidikan Stop Aksi Bullying. PKM-P, 4 (1)

I. Sundarta, A. Sari and H. P. Wibowo, "Pengelolaan Limbah Organik Menjadi Kompos melalui Pembuatan Tong Super" Jurnal Pengabdian Pada Masyarakat, 2018.

Prasetya, E. (2018). Pemberdayaan Masyarakat Tentang Kesehatan, Pendidikan dan Kreatifitas. Abdi Dosen: Jurnal Pengabdian Pada Masyarakat 2 (1), 19-25.

Nasution, A.S., Gurning, F.P., Pratama, M.Y., Fauzan. (2020). Risk factors for diabetes mellitus occurrence in the elderly at the griya antapani public health center. Indian Journal of Forensic Medicine and Toxicology.
Internet:

http://pkm.uikabogor.ac.id/index.php/ABDIDOS/iss ue/archive

http://pkm.uikabogor.ac.id/index.php/pkm-p

https://bulelengkab.go.id/bankdata/pengerti an-posyandu-kegiatandefinisi-tujuanfungsi-manfaat-dan-pelaksanaanposyandu-33

https://id.m.wikipedia.org/wiki/Zebra_cross

https://www.google.com/amp/s/desabanyio r.wordpress.com/2014/07/21/penyulu han-kewirausahaan-masyarakat-desabanyior/amp/

https://www.google.com/search?q=tujuan+ dari+program+keagamaan\&oq=tujua $\underline{\mathrm{n}+\text { dari }}+$ program+keagamaan $+\& \mathrm{aqs}=$ chrome..69i57j0.9553j0j4\&client $=m s$ -android-xiaomi\&sourceid=chromemobile \&ie $=\mathrm{UTF}-8$ 